\title{
In vivo investigation of antihyperalgesic and antinociceptive effects of peat formulations
}

PLAMEN IVANOV ZAGORCHEV ${ }^{1}$

ELISAVETA GEORGIEVA APOSTOLOVA ${ }^{2 *}$ BISSERA ASENOVA PILICHEVA

MILENA NENKOVA DRAGANOVA-FILIPOVA ${ }^{4,5}$ VESELA YULIEVA KOKOVA ${ }^{2}$

JULIAN BORISOV LUKANOV ${ }^{1}$

${ }^{1}$ Department of Biophysics, Faculty of Pharmacy, Medical University-Plovdiv 4000 Plovdiv, Bulgaria

${ }^{2}$ Department of Pharmacology and Drug Toxicology, Faculty of Pharmacy, Medical University-Plovdiv, 4000 Plovdiv, Bulgaria

${ }^{3}$ Department of Pharmaceutical Sciences, Faculty of Pharmacy, Medical University-Plovdiv, 4000 Plovdiv, Bulgaria

${ }^{4}$ Department of Medical Biology, Medical Faculty, Medical University-Plovdiv 4000 Plovdiv, Bulgaria

${ }^{5}$ Technological Center of Emergency

Medicine, 4000 Plovdiv, Bulgaria

\begin{abstract}
The aim of this study is to evaluate the antihyperalgesic and antinociceptive effects of two formulations containing peat water extracts using a model of carrageenan-induced hyperalgesia, combined with a test with a mechanical stimulus, and a hot plate test. Rats were divided into seven groups $(n=6)$ and received local treatment with two peat formulations and two diclofenac formulations dissolved in carbopol gel and Wolff ${ }^{\circledR}$ basis creme, respectively. Carbopol gel, Wolff ${ }^{\oplus}$ basis creme and $0.9 \%$ $\mathrm{NaCl}$ without tested substances were used as controls. Both peat formulations exerted an unambiguous antihyperalgesic effect 60 minutes after the treatment. In the hot plate test, the rats treated with the Wolff ${ }^{\circledR}$ basis creme peat formulation showed a tendency to prolonged latency on the first hour. The results could be explained by partial activation of peripheral $\alpha_{2}$-adrenoceptors and the possible COX-2 suppressive activity.
\end{abstract}

Keywords: peat, hyperalgesia, Wistar rats

Accepted March 22, 2018

Published online April 27, 2018

Peat is a natural material characterized by a wide range of pharmacological effects and antibacterial (1), wound healing (2), antiviral properties (3). It has been found effective in the treatment of dermatitis, psoriasis and rheumatoid arthritis $(2,4)$. The most active components of the peat water extract are fulvic and ulmic acids (5). A clinical trial has proved the efficacy of fulvic acid in the treatment of eczema (6). Fulvic acid has been found to exhibit anti-inflammatory effects and wound healing properties in vivo (7). Our previous research showed that the peat water extract is a specific cyclooxygenase-2 (COX-2) inhibitor (8). Even though the anti-inflammatory effect of peat has been already reported, its effect on the hyperalgesia and nociception has not been studied enough.

\footnotetext{
*Correspondence; e-mail: apostolova1212@gmail.com
} 
For the purposes of the present study, we selected two hydrophilic formulations, namely, a hydrogel and a hydrophilic cream, as delivery systems for the water-soluble compound found in peat.

The aim of this study is to evaluate the antihyperalgesic and antinociceptive effects of two formulations containing water extracts of peat. For these purposes, we used i) a model of carrageenan-induced hyperalgesia, combined with a nociceptive test with a mechanical stimulus, and ii) a nociceptive test with a thermal stimulus (hot plate test).

\section{EXPERIMENTAL}

\section{Materials}

The substances and marketed products used in the experiments and their respective producers and distributors are listed: peat (Wulfes Neudorf-Platendorf, Germany), acetonitrile (Merck, Germany), trifluoroacetic acid (Sigma Chemical Co., USA), Carbopol 934 (Sigma Aldrich, USA), triethanolamine (Alfa Aesar, USA), Wolff ${ }^{\circledR}$ basis creme (Dr. WolffGruppe $\mathrm{GmbH}$, Germany), carrageenan (Fluka, Germany), diclofenac sodium (Ph. Eur.).

\section{Animals}

Male Wistar rats (weighing 125-250 g) were kept under standard laboratory conditions (temperature $22 \pm 1{ }^{\circ} \mathrm{C}$, humidity $45 \%$, 12-h dark/light cycle, food, and water ad libitum). The experiments were approved by the Bulgarian Food Safety Agency (permit number: 88/09.01.2014) and the Ethics Committee of the Medical University-Plovdiv, Bulgaria (approval number: 1/22.01.2015).

\section{HPLC analysis of peat}

The analysis was performed as described previously (1). Briefly, an HPLC-System of Perkin-Elmer (Arcade, USA) was used. The equipment consisted of an autosampler (ISS 200), diode array detector (Diode Array LC 235C), quaternary pump (Series 200 LC, Perkin-Elmer), column thermostat (LC Oven 101 CC5904762), gas removal equipment (Series 200 online degasser), sample collector (FC 203B; Gilson, USA), and interface (600 Link, Perkin-Elmer). Parameters of the analytical column: Supelcosil RP C18 $250 \times 4.6 \mathrm{~mm}, 5 \mathrm{~m}$ (Supelco, USA). Mobile phase A consisted of $99.95 \%$ acetonitrile and $0.05 \%$ trifluoroacetic acid (TFA). Mobile phase C consisted of $99.95 \%$ water and $0.05 \%$ TFA.

\section{Sample preparation}

Briefly, $20 \mathrm{~g}$ bidistilled water was added to $100 \mathrm{~g}$ fresh peat and a suspension was obtained. After one day storage at $25^{\circ} \mathrm{C}, 1 \mathrm{~g}$ of this suspension was measured and centrifuged using a laboratory centrifuge 400R (Heraeus Instruments, Germany) for $20 \mathrm{~min}$ at $3000 \times \mathrm{g}$ at $25^{\circ} \mathrm{C}$.

The supernatant was filtered ( $0.45 \mu \mathrm{m}$ filter, Sartorius, Germany) and a clear, brownish liquid was collected. It did not show any sign of sedimentation at room temperature for several weeks or at a temperature of $+2{ }^{\circ} \mathrm{C}$ for several days.

The samples $(n=5$, volume $=25 \mathrm{~mL})$ were subjected to evaporation at a pressure of 0.63 mbar $\left(63 \mathrm{~N} / \mathrm{m}^{2}\right)$ for $8 \mathrm{~h}$ at a temperature of $+1{ }^{\circ} \mathrm{C}$ and the concentrated samples were centri- 
fuged at $25^{\circ} \mathrm{C}$ and $3000 \times g$ for $10 \mathrm{~min}$. The sediment was removed and the liquid was filtered through a membrane filter $(0.45 \mu \mathrm{m})$. A volume of $160 \mu \mathrm{L}$ was injected into the HPLC system. All samples were examined at $\lambda=(205 \pm 5) \mathrm{nm}$.

\section{Preparation of semisolid formulations}

The water extract was concentrated and desiccated using a freeze dryer Alpha 1-4 (Martin Christ Gefriertrocknungsanlagen $\mathrm{GmbH}$, Germany) until a concentration of $1 \%(\mathrm{~m} / \mathrm{m})$ was obtained. Semisolid formulations were prepared with the desiccated water extract.

\section{Preparation of carbopol gels}

A required amount of Carbopol $934(1 \%, \mathrm{~m} / \mathrm{m})$ was dispersed in distilled water and the aqueous dispersion was allowed to hydrate for 2 hours. Propylene glycol $(10 \%, \mathrm{~m} / \mathrm{m})$ was added subsequently to the aqueous dispersion to prevent water loss. The carbopol dispersion was further neutralized with triethanolamine under gentle stirring and $\mathrm{pH}$ was adjusted to 6 . A specific amount of the dried water extract $(1 \%, \mathrm{~m} / \mathrm{m})$ was dry ground in a mortar followed by wet grinding with the help of the prepared carbopol gel. The semisolid mixture was gently stirred with a spatula until a homogeneous gel was formed.

For the preparation of diclofenac gel, an accurately weighed amount of the non-steroidal anti-inflammatory drug (NSAID) diclofenac $(1 \%, \mathrm{~m} / \mathrm{m})$ was dissolved in distilled water and the solution was added to the carbopol dispersion prior to neutralization.

\section{Preparation of creams}

A marketed Wolff ${ }^{\circledR}$ basis creme (WB creme) was used as the base for the preparation of peat/diclofenac cream formulations. A specific amount of dried water extract of peat / diclofenac sodium $(1 \%, \mathrm{~m} / \mathrm{m})$ was ground in a mortar with the help of the base. The mixtures were gently stirred with a spatula until a homogeneous cream was formed. Three control groups were used in the experiment: saline $(0.9 \% \mathrm{NaCl})$, placebo carbopol gel and placebo WB creme for the two types of formulations, respectively. Formulations and the groups treated are shown in Table I.

Table I. Abbreviations and composition of the formulations used in the experiments

\begin{tabular}{|c|c|c|}
\hline Group number & Abbreviation & Composition \\
\hline 1 & control & Saline $(0.9 \% \mathrm{NaCl})$ \\
\hline 2 & carbopol & Placebo carbopol gel \\
\hline 3 & WB creme & Placebo Wolff ${ }^{\circledR}$ basis creme \\
\hline 4 & PG & Carbopol gel + water extract of peat \\
\hline 5 & PC & Wolff ${ }^{\circledast}$ basis creme + water extract of peat \\
\hline 6 & DG & Carbopol gel + diclofenac \\
\hline 7 & DC & Wolff $^{\circledR}$ basis creme + diclofenac \\
\hline
\end{tabular}




\section{Antihyperalgesic effect}

Forty-two rats were divided into seven groups $(n=6)$. Group numbers and their composition are given in Table I. Groups 6 and 7 were used as positive controls. The antihyperalgesic effect of the formulations was tested on the same animals one day after the hot plate experiment. The rats received $1 \mathrm{~mL}$ of the formulations and the amount was spread solely on the skin of the rat's right hind paw. The paw was massaged to allow skin penetration. An injection of $0.1 \mathrm{~mL}$ carrageenan $(1 \%(\mathrm{~m} / \mathrm{V})$ suspension in saline) was administered on the same paw after the treatment (9).

The pain threshold of the rats was tested with an Analgesy-Meter (Ugo Basile, Italy) immediately after the application of formulations. The right hind paw of the rat was subjected to gradient increasing pressure $\left(16 \mathrm{~g} \mathrm{~s}^{-1}\right)$, which was applied to the paw between the third and fourth metatarsal joint. The point at which the rat withdraws the paw is the nociceptive threshold, measured in PPT-units. The cut-off limit of the apparatus is $250 \mathrm{~g}$ (maximum possible mechanical pressure). Subsequent measures were taken 60, 120 and 180 minutes after the treatment.

\section{Antinociception with thermal stimulus (Hot plate test)}

The plantar surface of all rat paws was treated topically with the formulations described in Table I, and each rat received $1 \mathrm{~mL}$ of the formulation. Immediately before the application and 30, 60, 90 and $120 \mathrm{~min}$ after the treatment, the antinociceptive effect was studied using the hot plate test. The test was conducted as described before (10). The animals were placed on a metal plate (temperature of $55 \pm 0.5^{\circ} \mathrm{C}$ ). Any sign of nociception (licking a hind paw, vocalization, or an escape attempt) was used as the endpoint of the test and the animal was returned to its cage. Latency was detected and reported as mean \pm SEM. The cut-off time for the experiment was $30 \mathrm{~s}$ to minimize the risk of thermal injury of the paws.

\section{Statistics}

The SPSS 19.0 program was used for statistical analysis of the results. Normal distribution was evaluated with a One-sample Kolmogorov-Smirnov test. All data showed normal distribution. One-way ANOVA and the Bonferroni post hoc test were performed. Data are shown as mean \pm SEM. Results were considered significant at $p<0.05$.

\section{RESULTS AND DISCUSSION}

\section{HPLC analysis}

As shown in Fig. 1, a well-defined peak with a retention time of 12.45 minutes was detected. The chromatographic profile of the water extract is similar to previously reported results (1). The fraction with a retention time of 12.45 min may exert an agonistic effect on dopamine D2 receptors and $\alpha_{2}$-adrenoceptors (5).

\section{Antihyperalgesic effect}

We registered a well-defined antihyperalgesic effect in the test with mechanical stimulation in rats treated with both tested peat formulations - PG and PC at the $60^{\text {th }}$ minute of 


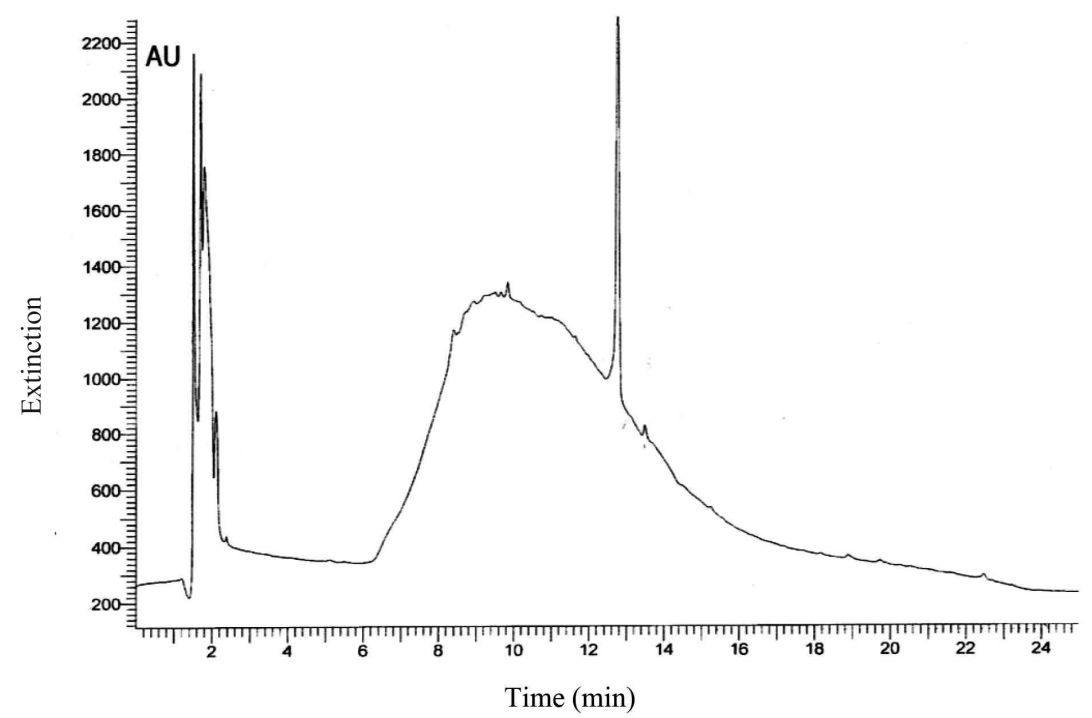

Fig. 1. Chromatographic profile (HPLC) of water extract of peat. Absorbtion at $205 \mathrm{~nm}$.

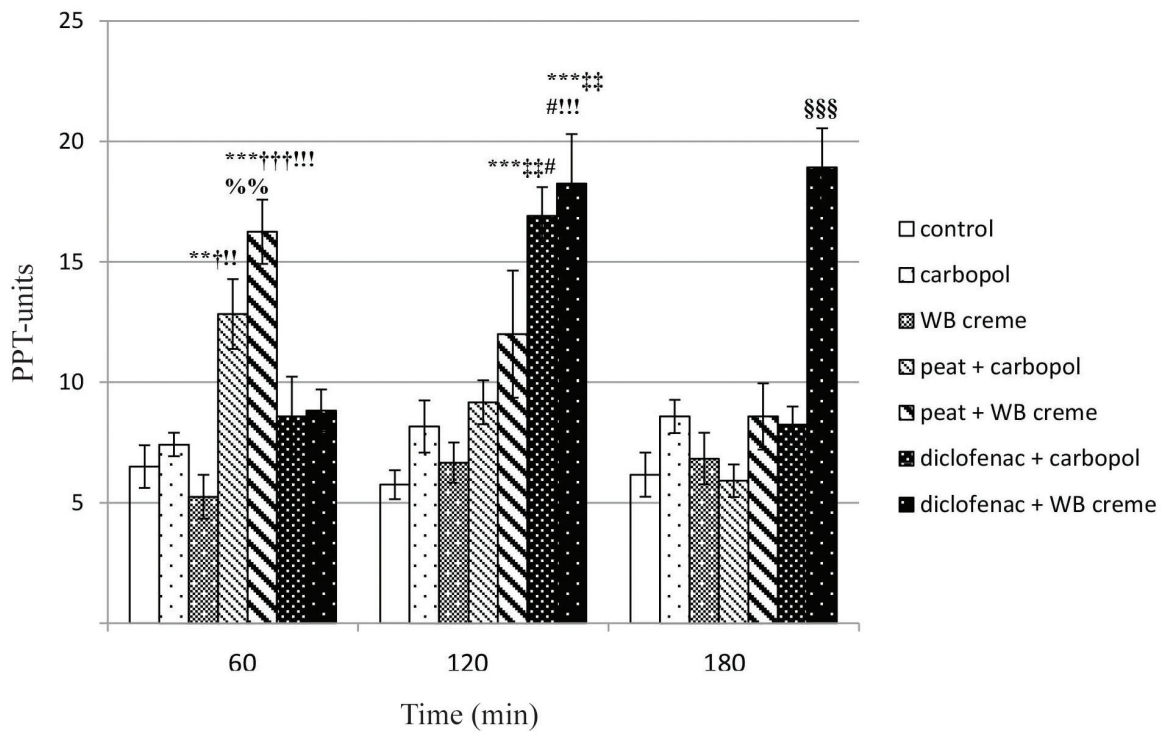

Fig. 2. Evaluation of the antihyperalgesic effect of two peat formulations in rats (carrageenan-induced hyperalgesia). Data are shown as mean $\pm \operatorname{SEM}(n=6)$.

${ }^{* *} p<0.01$ vs. controls; ${ }^{* * *} p<0.001$ vs. controls; ${ }^{+} p<0.05$ vs. carbopol; ${ }^{+++} p<0.001$ vs. carbopol; " $p<0.01$ vs. WB creme; "'! $p<0.001$ vs. WB creme; ${ }^{\%} \% p<0.01$ vs. diclofenac+carbopol and diclofenac+WB creme; ${ }_{\sharp \ddagger} p<0.01$ vs. carbopol and WB creme; ${ }^{\sharp} p<0.05$ vs. peat+carbopol; $\$ \$ s \$<0.001$ vs. controls, carbopol, WB creme, peat+carbopol, peat+WB creme and diclofenac+carbopol. 
the experiment. The effect was diminished in the second hour. The rats treated with both diclofenac preparations showed increased PPT units in the second hour of the experiment. The effect persisted to the third hour only in the DC group (Fig. 2). The results implicated that the antihyperalgesic effect of the water extract of peat reached its maximum at the $60^{\text {th }}$ minute of the experiment, while the NSAID diclofenac was most active at the $120^{\text {th }}$ minute.

Activation of primary sensory afferent neurons plays a major role in inflammatory pain. A wide range of inhibitory receptors (e.g. opioid, $\alpha$-adrenergic, adenosine, 5-HT and $\mathrm{GABA}_{\mathrm{A}}$ ) are present in the peripheral nerve endings (11).

The water extract of peat acts as a partial agonist of $\alpha_{2}$-adrenoceptors, as reported before (1). Activation of $\alpha_{2 \mathrm{~A}}$ - and $\alpha_{2 \mathrm{C}}$-adrenoceptors is involved in the antinociceptive effect (11). Moreover, Honda et al. (2015) reported that dexmedetomidine (a selective $\alpha_{2}$ adrenoceptor agonist) diminished the hyperalgesic effect of carrageenan when injected locally into an inflamed hind paw of rats (12). The effect was abolished by local injection of yohimbine, which supports the suggestion of involvement of peripheral $\alpha_{2}$-adrenoceptors in the antihyperalgesic effect of dexmedetomidine.

It was previously reported that the peat water extract could act as a selective COX-2 inhibitor $(8,13)$. These results suggest that the mechanism of the antihyperalgesic effect of the peat water extract is more complex and involves not only partial activation of peripheral $\alpha_{2}$-adrenoceptors but also COX-2 inhibition.

It has been proved that both fulvic and ulmic acids possess selective permeability through human skin (1). Their concentrations in the formulations are sufficient to provide the antihyperalgesic effect, having agonistic activity on the peripheral $\alpha_{2}$-adrenoceptors.

\section{Antinociception with thermal stimulus (Hot plate test)}

As shown in Fig. 3, the formulations containing the NSAID diclofenac showed a welldefined antinociceptive effect. Its peak was reached at the $60^{\text {th }}(\mathrm{DG})$ and $90^{\text {th }}$ minute (DC) after the treatment. At the 60th minute, a significant increase in the latency was detected in the DG group $(19.57 \pm 2.17)$ compared to the control group $(9.92 \pm 1.43)$ and WB creme group (8.38 \pm 1.57 ) (Fig. 3). Increased latency was registered also in the DC group, when compared to the controls, carbopol and WB creme groups (22.08 \pm 2.59 vs. $9.92 \pm 1.43 ; 11.37 \pm$ 1.74 and $8.38 \pm 1.57$, respectively). A tendency of increased latency was also observed in the rats treated with peat formulations on the $30^{\text {th }}$ and $60^{\text {th }}$ minute; however, statistical significance was not reached.

On the 90th minute after the application, the DG treatment increased latency compared to the controls, WB creme, and PG $(20.45 \pm 1.30$ vs. $9.37 \pm 1.42,6.95 \pm 0.60$ and $9.30 \pm 1.33$, respectively). A significant antinociceptive effect was also shown by the group treated with DC compared to the controls, WB creme and PG $(18.73 \pm 2.24$ vs. $9.37 \pm 1.42,6.95 \pm 0.60$ and $9.30 \pm 1.33$, respectively).

The water extract of peat and its components fulvic and ulmic acids are characterized by partial agonistic activity on $\alpha_{2}$-adrenoceptors and dopamine D2 receptors. Magnusson et al. reported the involvement of dopamine D2 receptors in the dorsolateral striatum in nociception (14). 


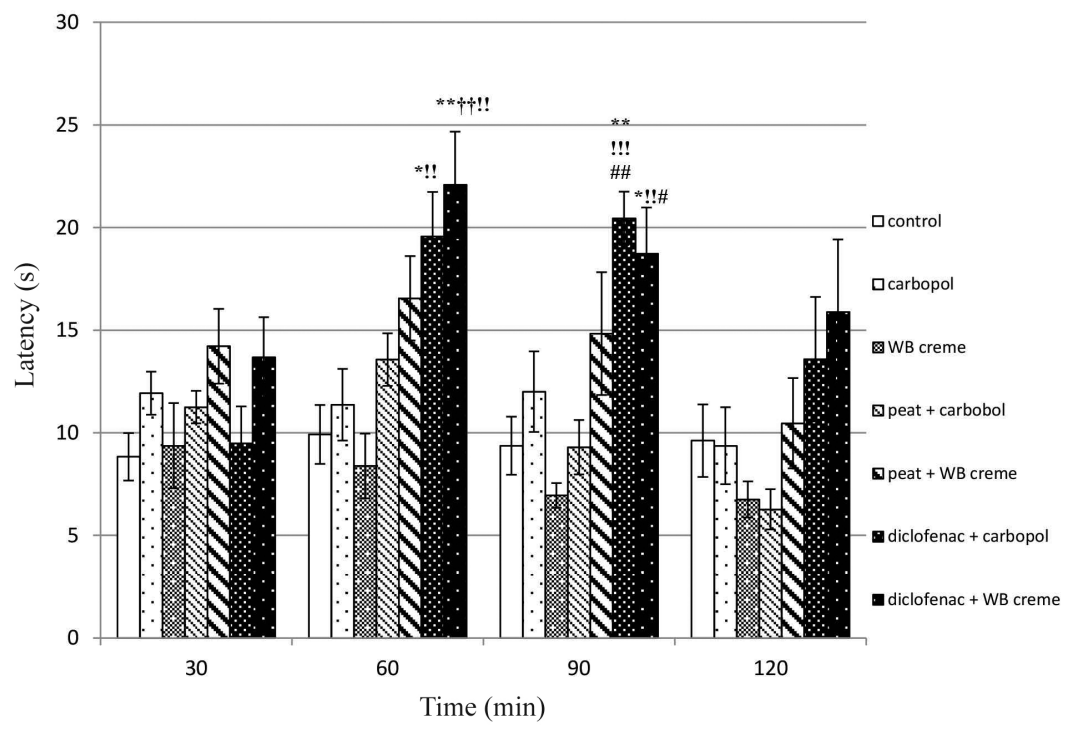

Fig. 3. Evaluation of the antinociceptive effect of two peat formulations (hot plate test). Data are shown as mean $\pm \operatorname{SEM}(n=6)$.

${ }^{*} p<0.05$ vs. controls; ${ }^{* *} p<0.01$ vs. controls; ${ }^{++} p<0.01$ vs. carbopol; $"$ p $p<0.01$ vs. WB creme; "' $p<0.001$ vs. WB creme; ${ }^{\#} p<0.05$ vs. peat + carbopol; ${ }^{\# \#} p<0.01$ vs. peat + carbopol.

Activation of dopamine D2 receptors and $\alpha_{2}$-adrenoceptors could explain the tendency of prolonged latency at the $60^{\text {th }}$ minute in rats treated with PC. However, the results did not reach statistical significance, probably due to the relatively low concentrations of water-soluble fulvic and ulmic acids in the central nervous system. The hot-plate test is usually used for evaluation of the central antinociceptive activity of drugs on acute, noninflammatory, nociceptive pain (15). Moreover, dopamine and noradrenaline are not the only mediators with a crucial role in the nociception in the hot plate test (15).

\section{CONCLUSIONS}

The water extract of peat included in carbopol gel and WB creme exerts an unambiguous antihyperalgesic effect at the first hour after the treatment. The antihyperalgesic effect in carrageenan-induced hyperalgesia could be explained by the partial activation of peripheral $\alpha_{2}$-adrenoceptors and COX-2 inhibitory activity. The activation of dopamine D2 receptors and $\alpha_{2}$-adrenoceptors may explain the tendency of prolonged latency in rats treated with peat + WB creme at the 1st hour in the hot plate test. However, the central antinociceptive effect of the topical peat formulation with higher fulvic and ulmic acids concentration is a subject of future experiments. 


\section{REFERENCES}

1. A. M. Beer, H. E. Junginger, J. Lukanov and P. Sagorchev, Evaluation of the permeation of peat substances through human skin in vitro, Int. J. Pharm. 253 (2003) 169-175; https://doi.org/10.1016/ S0378-5173(02)00706-8

2. C. E. J. van Rensburg, The antiinflammatory properties of humic substances: a mini review, Phytother. Res. 29 (2015) 791-795; https://doi.org/10.1002/ptr.5319

3. R. Klocking, B. Helbig and P. Wutzler, Untersuchungen zur antiviralen Aktivität von polyanionischen Torfinhaltsstoffen in vitro und in vivo, Geburtsh. Frauenheilk. 60 (2000) 192.

4. S. Codish, M. Abdu-Shakra, D. Flusser, M. Fringer and S. Sukenik, Mud compress therapy for the hands of patients with rheumatoid arthritis, Rheumatol. Int. 25 (2005) 49-54; https://doi.org/10.1007/ s00296-003-0402-4

5. A. M. Beer, J. Lukanov and P. Sagorchev, Isolation of biologically active fractions from the water soluble components of fulvic and ulmic acids from peat, Phytomedicine 9 (2002) 653-666; https:// doi.org/10.1078/094471102321616490

6. J. J. Gandy, J. R. Snyman and C. E. van Rensburg, Randomized, parallel-group, double-blind, controlled study to evaluate the efficacy and safety of carbohydrate-derived fulvic acid in topical treatment of eczema, Clin. Cosmet. Investig. Dermatol. 4 (2011) 145-148; https://doi.org/10.2147/CCID. S23110

7. R. Sabi, P. Very and C. E. J. van Rensburg, Carbohydrate-derived fulvic acid (CHD-FA) inhibits carrageenan-induced inflammation and enhances wound healing: efficacy and toxicity study in rats, Drug Dev. Res. 73 (2011) 18-23; https://doi.org/10.1002/ddr.20445

8. A. M. Beer, P. Zagorchev, M. Filipova and J. Lukanov, Effects of aqueous peat extract on the activity of cyclooxygenase and cyclooxygenase-1 and cyclooxygenase-2 isoforms, Phys. Med. Rehab. Kuror. 25 (2015) 51-54.

9. S. Porzio, G. Caselli, L. Pellegrini, V. Pallottini, M. Del Rosario, A. Coppola, L. Boltri, M. Gentile, G. Clavenna and G. Melillo, Efficacy of a new topical gel-spray formulation of ketoprofen lysine salt in the rat: percutaneous permeation in vitro and in vivo and pharmacological activity, Pharmacol. Res. 37 (1998) 41-47; https://doi.org/10.1006/phrs.1997.0260

10. E. G. Apostolova, V. Y. Kokova and L. P. Peychev, Experimental study on the antinociceptive effect of retigabine in rats, IJBAMR. 5 (2015) 568-574.

11. R. M. Stepanović-Petrović, A. M. Micov, M. A. Tomić and N. D. Ugrešić, The local peripheral antihyperalgesic effect of levetiracetam and its mechanism of action in an inflammatory pain model, Anesth. Analog. 115 (2012) 1457-1466; https://doi.org/10.1213/ANE.0b013e31826c7fc2

12. Y. Honda, H. Higuchi, Y. Matsuoka, A. Yabuki-kawase, M. Ishii-maruhama, Y. Tomoyasu, S. Maeda, H. Morimatsu and T. Miyawaki, The inhibitory effect of locally injected dexmedetomidine on carrageenan-induced nociception in rats, Eur. J. Pharmacol. 764 (2015) 215-219; https://doi. org/10.1016/j.ejphar.2015.06.054

13. S. J. Chien, T. C. Chen, H. C. Kuo, C. N. Chen and S. F. Chang, Fulvic acid attenuates homocysteine-induced cyclooxygenase-2 expression in human monocytes, BMC Complement. Altern. Med. 15 (2015) 61; https://doi.org/10.1186/s12906-015-0583-xJ

14. E. Magnusson and K. Fisher, The involvement of dopamine in nociception: the role of $\mathrm{D}(1)$ and $\mathrm{D}(2)$ receptors in the dorsolateral striatum, Brain Res. 855 (2000) 260-266; https://doi.org/10.1016/ S0006-8993(99)02396-3

15. L. A. Pini, G. Vitale, A. Ottani and M. Sandrini, Naloxone-reversible antinociception by paracetamol in the rat, J. Pharmacol. Exp. Ther. 280 (1997) 934-940. 